\title{
Syntactic Variability in Spoken English Discourse through Age Dimensions
}

\author{
Karen Velyan \\ Yerevan State Linguistic University
}

\begin{abstract}
A $\mathrm{s}$ is widely known, English is socially and functionally differentiated, which is particularly true of the spoken variety of English. Social heterogeneity is bound to be reflected in language heterogeneity, especially in the syntactic patterns that native speakers use in conversational discourse.

It has often been claimed that speech forms have a range of associations, if not direct relations, with social categories, such as socio-economic class, gender, and age, which are considered to be social variables.

The latter may have reflections in linguistic variables, which then become socio-linguistic variables. It should be mentioned that both social and linguistic variables have different variants, that is why they are called variables. The correlation of linguistic variables with social variables such as social class and gender has in fact been the major focus of sociolinguistic study. Actually, it is these social variables that explain differentiation in language. Many linguists believe that "gender may in fact, be more powerful underlying cause for the social differentiation of language than socioeconomic status" (O'Grady, Dobrovolsky, Aronoff 1997:512). "A more viable approach is one that combines gender and other categories like social class" (Mesthrie et al. 2009:102).

Still, the correlation of linguistic variables with age as a social variable has not been paid due attention. And this is highly relevant to the correlation of syntactical variables with different age groups. As the American linguist Jeane Herndon puts it, “...individuals differ in the ways that they use their language from one period of their lives to another" (Herndon 1970:112). The correlation of syntactic features with age as a social variable is emphasized by Peter Trudgill as well: "The diffusion of a syntactic feature through a society may be halted by a social barrier such as socialclass, age, race, religion" (Trudgil 2000:24). Native speakers are believed to possess different range of vocabulary and syntactical structures in different time periods of their lives. Also, as time goes by, people are bound to interact in different social situations at different stages of their lives, which can ultimately result in picking up and acquiring new syntactical features of phrasing. Still, syntactic heterogeneity as related to different age groups has not been thoroughly studied.The study of the use of syntactic patterns through age dimensions can bring about some peculiarities of linguistic behavior in the spoken variety of English.

In this article, we will test the hypothesis that syntax of a native speaker is liable to change at different stages of his/her life. Wewillanalyze the syntactical features of native speakers of English belonging to two different age categories. One age category in our analysis ranges from $\mathbf{2 0}$ to $\mathbf{2 6}$, and the other - from $\mathbf{3 5}$ to $\mathbf{5 0 .}$

The material for the analysis is based on the face-to-face interviews with native speakers - both males and females.The interviews were first tape-recorded and then stenographed. To ensure communicative equality, all the informants were asked the same
\end{abstract}


questions. The interviews were held in informal settings. The informants were randomly chosen. As young speakers, we chose BA and MA students with different regional backgrounds. The informants of the second age group were university professors with different regional backgrounds, mostly ESL instructors. In the analysis, the factor of gender was taken into consideration, too.

The primary focus of the analysis was on such syntactic variables as types of composite sentences and the conjunctions used in simple and composite sentences.

The main objective of the analysis was to disclose the different proportions in the use of the sociolinguistic variables mentioned above and show the tendency and the statistical differential features rather than exclusive differential features in their use. This being the case, the analysis carries more quantitative rather than qualitative character.As a result of our analysis, we came to the following findings.

1. One of the most striking characteristics in spoken English discourse of young speakers, as our records data indicate, is the frequent use of the conjunction and in the front- and especially mid-sentential positions of the sentence, which can be illustrated by the following piece of an interview with a 20 -year old undergraduate student:

K.V.: Why did you choose up music?

R.M.: It all started when I was 12 years old.

K.V.: And...

R.M.:Andthere was this party that I went to, and we were playing "truth and day". We were sitting around in a circle. I said "truth", and they said: "You said truth six times, and there is nothing interesting at all". And so I said: "Ok. Day", and so they said: "Go play the piano". And so I did, and I loved it. And I said: "I wanna do this for the rest of my life". And I went to study it at UT.

The same syntactic feature is observed in the discourse of middle-aged speakers, since here again we notice the highest frequency of the use of the conjunction and. Moreover, we can state that the frequency of the use of the conjunction and in the discourse of this age group is even higher, almost twice as high. Also, male speakers tend to use it with a higher frequency than do female speakers, which is not the case with younger speakers.

In terms of frequency of usage, next comes the conjunction but in the front position of simple declarative and in compound sentences. Our data indicate that this conjunction has equal frequency of use on the part of male and female speakers among young speakers, which testifies to gender-related linguistic universal. This is not the fact in case of adult speakers. Thus, female speakers display significantly higher frequency of use of this conjunction. In terms of age-related linguistic differences, we can conclude that the conjunction but has a higher degree of use in the talk of young speakers than in the talk of middle-aged speakers. Here are two interviews with young (1) and middle-aged (2) speakers: 
1. K.V.: So, Cristine, would you please tell me what's your best, .favorite place in the United States or in Texas or in Austin, wherever?

Cristie:Am, my favorite place in the United States is Texas. Am ...I was... K.V.: Mine too.

Christine: Yes, I was born here, raised all but two years, I just love it ...because it has everything, has topographically, mountains, ocean and praire everything like that. but it also has ..different cultures. Am...You can go to any different city. My favorite place, my favorite city in the United State is Charlestown, South Carolina, so if we could just transplant it to Texas, it would be perfect

K.V.: OK And...how do you find study... at UT, or how do you find your life at UT?

Cristine.Am...I would love... UT, I ... I wasn't happy about going here in the first place, because I wanted to go to a different school, but didn't get in, and now... I can't imagine going to anywhere else. I mean I don't even know why the heck I wanted to leave Texas. Am...Everybody always told me that UT was so big that you are just a number, but I don't feel that way at all, and are for the most really eager to help you with prep sessions and things like that, so it is not as big as you would think it to be it the largest university in the country.

2. K.V: Terry, will you please tell me why and how you chose your major. A couple of words about it.

Terry: Aha. It's very interesting (laughing). I don't know... I just fell into that, I guess. I was working... Well, I first graduated with my Bachelor's degree. I worked for a number of years and was really bored with what I was doing. So I decided to go back to graduate school. And my undergraduate degree was in English literature. And so I actually applied for an English degree for a Master's. But within that program they happened to have an ESL specialization. So I started taking classes in linguistics. And doing some ESL work, like tutoring and things like that, I really enjoyed it. Am... so I ended up with specialization in my master's program in ESL.And then, when I started doing my PhD work, I switched to linguistics. So the first semester I was here at UT, I was actually in linguistics department. And then I decided it's too formal for me ..., so I transferred to education. And here I am (laughing).

Another feature that stands out in the conversational discourse of young American speakers is the relative frequency of attributive clauses. From cross-gender-linguistic perspective, attributive non-restrictive continuative clauses seem to be more characteristicof male speakers, while attributive non-restrictive clauses, including descriptive ones, are more characteristic of female speakers. Here is a piece of the interview with a 20-year female student: 
K.V.: Ok. In this conjunction, how do you find the academic life at UT? Jenifer: At UT? I've been enjoying it very much. I sort of was of type that would ... a...got a class and drop it. Within the first day, if I didn't think it was going be warnings, so I always am... when I around the class till I found a professor that was very expert and the field, and he was enjoyable teacher. And... I liked discussions in classes. I think that's good, too. I was fortunate I had a plantiniun studio ... my major classes room really small, so really good to know the professors and the students.

In the talk of adult speakers, this kind of clauses, especially attributive restrictive clauses, were more frequently met. As opposed to the young age group, in this age group it is female speakers that use attributive clauses a lot more than do male speakers. As far as attributive non-restrictive clauses are concerned, they display tendency to be used far oftener than they are used in the talk of young female speakers. Here is a piece of the interview with a 52-year-old ESL professor:

K.V: Ok. So, sticking to foreign language education, would you please tell me why and how you ended up taking up this major, foreign language education?

Pat: Ok. Well, of course, as you can see by the fact that I chose education and English and Spanish, I was already linked to foreign language education as a... as a young person, and just loved ... the other language, which in my case was Spanish, and liked the culture of the language that I deal with. Am..And so I continued with that for a while. But am...one time, when I was fairly young, while I was not teaching in school, but was at home with my children, I was asked to do some voluntary work for a an organization at Peru University called "Wives of the World", which was like our community programs here at UT serving the families of the graduate students at UT. And as a voluntary I started out baby-sitting for them while they had their English. I continue to love it, because here ... in this job ... I was feeling like ... I am teaching something, I am giving something, but I am learning more from the students than they are learning from me.

Another syntactical feature that stands out in the conversational discourse of American students is the relative frequency of adverbial clauses of reason introduced by the conjunction because. It is very typical of American students to begin a sentence with the conjunction "because", sometimes abbreviating it to "cause". It has been our observation that American female speakers tend to use it more frequently than male speakersdo. Here is another piece of the interview with the 20 -year-old female student:

K.V.: Jennifer, would you please tell me how you ended up taking arts, which has become your ... major for the last three years? 
Jennifer: Well, basically, am...I've always ...well to drive in communicating through that. And... I ... am.. I was interested in al...am ... academia, but I liked art. best, because it kind of would give you own spin on what you are learning. And ... I am also interested in studying am... I am actually thinking about... The reason I am stopping at UT, Austin is I am going to different schools to continue in arts but to actually study art therapy.

K.V.: So, art therapy is supposed to be your ..sub major.

Jeniffer: Yeah, I... I wanted to go to graduate art therapy at high school, so I want to add some psychology in to my classes. Cause I found out I was doing art am... For most I did was therapially needed it. And favorite experience is to work with students privately and kind of help them, kindofunvalue their talents and their feelings through the art.

The same kind of tendency is observed in the discourse of adult speakers. However, the cases with the front position of the conjunction because turn out to be fewer. This last factor speaks in favor of the fact that the syntax of native speakers gets more standardized as they get maturity.

K.V.: Susan, what's your favorite place in the United States or in Texas? Otherwise put, where would you like to live if given a chance?

Susan Kerr: Well, Texas is an interesting state. I need to talk about the big picture of Texas first, because ... we're urban state. We, fortunately, we have a number of interesting cities. And Texans characterize their cities in different ways. They say that Houston and Dallas are the wallet of Texas, the banking center. Austin is supposed to be the branch of Texas, cause this is where the big university and the government is. And San Antonio is supposed to be the soul of Texas. That's where the artists are.

Of course, our descriptive analysis was not aiming at giving a full picture of conversational syntax of American speakers of different age categories. Our goal was to point out some of the key syntactical features in the talk of native speakers in the United States, which have turned out to be the frequent usage of the conjunction and, but, attributive clauses, adverbial clauses with because. Thus, as we see syntax functions differently in different periods of life, which is the valid indicator socio-linguistic variability in different age groups.

\section{References:}

1. Herndon, J. (1970) A Survey of Modern Grammars. New York: Holt, Rinehart and Winston, Inc.

2. Trudgill, P. (2000) Sociolinguistics. An Introduction to Language and Society. USA: Penguin Books. 
3. Mesthrie, R.; Swann, J.; Deumert, A.; Leap, W.L. (2009) Introducing Sociolinguistics. Second Edition. Edinburgh: EUP.

4. O'Grady, W.; Dobrovolsky, M.; Aronoff, M. (1997) Contemporary Linguistics. AnIntroduction. Third Edition. New York: St. Martin's Press.

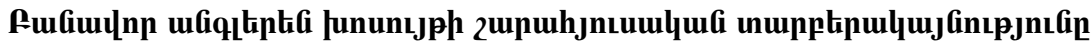 unupppujpGi unufiáfiuhumlpnıpjnıfititph [nıJuh Gitppn}

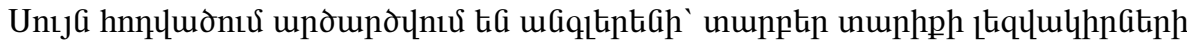

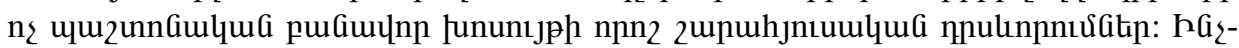

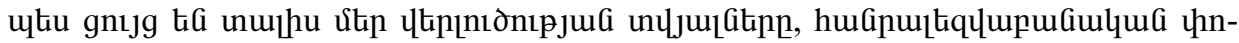

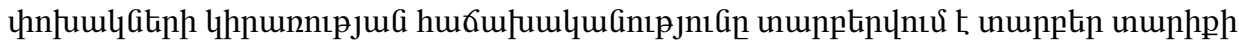

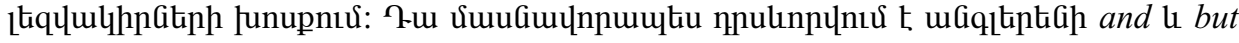

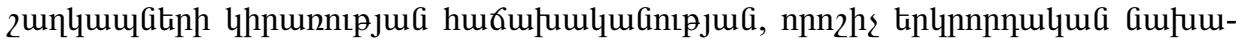

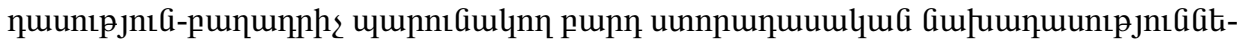

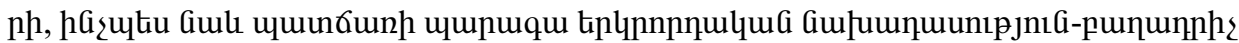

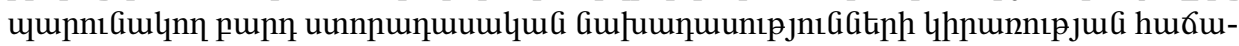
juulumGinıpjua unnıunц: 